\title{
Erratum
}

\section{Deriving the mean primary-particle diameter and related quantities from the size distribution and the gravimetric mass of spark generated nanoparticles}

Klaus Wittmaack

GSF-National Research Centre for Environment and Health, Institute of Radiation Protection, 85758, Neuherberg, Germany (Tel.: +49-89-3187-2439; E-mail: wittmaack@gsf.de)

\section{Erratum to: Journal of Nanoparticle Research}

DOI 10.1007/s11051-006-9127-0

(1) With reference to Table 1:

The footnote text is erroneously given as:

*The mass density of $\mathrm{C}(\operatorname{Ir})\langle 3 \mathrm{~nm}\rangle$ was assumed to be the weighted average of the two components The correct text is as follows:

*The mass density of $\mathrm{C}(\mathrm{Ir})\langle 33 \mathrm{~nm}\rangle$ was assumed to be the weighted average of the two components

(2) With reference to the Section Advanced data evaluation; Sub-section (ii); second paragraph:

The text is erroneously given as:

The mean diameters of the primary iridium particles range between 73.5 and $5.4 \mathrm{~nm}$.

The correct text is as follows:

The mean diameters of the primary iridium particles range between 3.5 and $5.4 \mathrm{~nm}$.

The online version of the original article can be found at http://dx.doi.org/10.1007/s11051-006-9127-0. 